\title{
Galvanic Corrosion Between AISI304 Stainless Steel and Carbon Steel in Chloride Contaminated Mortars
}

\author{
Xingguo Feng ${ }^{1,2,}$, Jianqu Liu $^{2}$, Cen Hang ${ }^{2}$, Zuocheng Lu², Yukun Jiang ${ }^{2}$, Yiwen $\mathrm{Xu}^{3}$, Da Chen ${ }^{1,2, *}$ \\ ${ }^{1}$ Jiangsu Key Laboratory of Coast Ocean Resources Development and Environment Security, Hohai \\ University, Nanjing 210098, Jiangsu, China \\ ${ }^{2}$ College of Harbour, Coastal and Offshore Engineering, Hohai University, Nanjing 210098, Jiangsu, \\ China \\ ${ }^{3}$ Dayu College, Hohai University, Nanjing 210098, Jiangsu, China \\ *E-mail: chenda@hhu.edu.cn
}

doi: $10.20964 / 2016.06 .24$

Received: 10 March 2016 / Accepted: 30 March 2016 / Published: 4 May 2016

Galvanic corrosion between AISI304 stainless steel and carbon steel in mortars has been studied by open circuit potential, electrochemical impedance spectroscopy, and galvanic coupling currents. The corrosion state of the coupling rebar was also examined after removing the mortars. The results suggest that the carbon steel presents a high risk of galvanic corrosion in the initial stage when it is electrically coupled with stainless steel in the chloride-contaminated mortars. However, for the stainless steel promotes the passivation of carbon steel, the risk of galvanic corrosion on carbon steel significantly decreased as the time extends. In addition, the water-cement ratio of mortars does not have a dramatic influence on the galvanic corrosion between stainless steel and carbon steel in the chloride-contaminated environment.

Keywords: Stainless steel, carbon steel, galvanic corrosion, concrete, electrochemical test.

\section{$\underline{\text { FULL TEXT }}$}

(C) 2016 The Authors. Published by ESG (www.electrochemsci.org). This article is an open access article distributed under the terms and conditions of the Creative Commons Attribution license (http://creativecommons.org/licenses/by/4.0/). 